\title{
BI-69A11 enhances susceptibility of colon cancer cells to mda-7/IL-24-induced growth inhibition by targeting Akt
}

\author{
I Pal ${ }^{1}$, S Sarkar ${ }^{2}$, S Rajput ${ }^{1}, \mathrm{~K}$ K Dey ${ }^{1}$, S Chakraborty ${ }^{3}, \mathrm{R} \mathrm{Dash}^{4}$, S K Das ${ }^{2,5}$, D Sarkar ${ }^{2,5,6}$, E Barile ${ }^{7}, \mathrm{~S} \mathrm{~K} \mathrm{De}^{7}$, \\ M Pellecchia ${ }^{7}$, P B Fisher ${ }^{\star}, 2,5,6$ and M Mandal ${ }^{\star, 1}$ \\ ${ }^{1}$ School of Medical Science and Technology, Indian Institute of Technology Kharagpur, Kharagpur, West Bengal 721302, India; \\ ${ }^{2}$ Department of Human and Molecular Genetics, Virginia Commonwealth University School of Medicine, Richmond, VA 23298, \\ USA; ${ }^{3}$ R.G.Kar Medical College, Kolkata, West Bengal 700004, India; ${ }^{4}$ Institute of Life Science, Bhubneswar, Odisha 751023, India; \\ ${ }^{5} \mathrm{VCU}$ Institute of Molecular Medicine, Virginia Commonwealth University, School of Medicine, Richmond, VA 23298, USA; \\ ${ }^{6}$ VCU Massey Cancer Center, Virginia Commonwealth University, School of Medicine, Richmond, VA 23298, USA and \\ ${ }^{7}$ Sanford-Burnham Medical Research Institute, La Jolla, CA 92037, USA
}

Background: Akt and its downstream signalling pathways contribute to the aetiology and progression of colorectal carcinoma (CRC). Targeting the Akt pathway is an attractive strategy but few chemotherapeutic drugs have been used to treat CRC with only limited success. BI-69A11, a small molecule inhibitor of Akt, efficiently inhibits growth in melanoma cells. Melanoma differentiation associated gene-7 (mda-7)/interleukin-24 promotes cancer-selective apoptosis when delivered by a tropism-modified replication incompetent adenovirus (Ad.5/3-mda-7). However, Ad.5/3-mda-7 displays diminished antitumour efficacy in several CRC cell lines, which correlates with the expression of K-RAS.

Methods: The individual and combinatorial effect of BI-69A11 and Ad.5/3-mda-7 in vitro was studied by cell viability, cell cycle, apoptosis and invasion assays in HT29 and HCT116 cells containing wild type or mutant K-ras, respectively. In vivo HT29 tumour xenografts were used to test the efficacy of the combination treatment.

Results: BI-69A11 inhibited growth and induced apoptosis in CRC. However, combinatorial treatment was more effective compared with single treatment. This combination showed profound antitumour and anti angiogenic effects in vitro and in vivo by downregulating Akt activity.

Conclusions: BI-69A11 enhances the antitumour efficacy of Ad.5/3-mda-7 on CRC overexpressing K-RAS by inducing apoptosis and regulating Akt activity thereby warranting further evaluation in treating CRC.

The phosphoinositide 3-kinase (PI3K)-Akt pathway has received significant attention in human tumourigenesis because it regulates multiple cellular activities including cell cycle, proliferation, growth, apoptosis, autophagy and protein synthesis (Bellacosa et al, 2005). The Akt super family consists of three members, AKT1, AKT2 and AKT3, that are composed of a conserved $\mathrm{N}$-terminal pleckstrin homology $(\mathrm{PH})$ domain, a central catalytic domain and a C-terminal regulatory hydrophobic motif (Vivanco and Sawyers, 2002; Hanada et al, 2004). Akt, a serine/threonine kinase, is one of the downstream targets of PI3K. Akt is activated owing to the formation of phosphatidylinositol $(3,4,5)$-triphosphate (PIP3) by PI3K. Phosphatidylinositol $(3,4,5)$-triphosphate binds with the $\mathrm{PH}$ domains of Akt and aids in the recruitment of Akt to the plasma membrane, which alters the conformation of Akt to allow for subsequent phosphorylation by phosphoinositidedependent kinase-1 (PDK1) (Vivanco and Sawyers, 2002). Akt is 
activated through the phosphorylation of Thr308, but phosphorylation of the Ser473 residue located at the hydrophobic C-terminal region is also required for full activation of the kinase (Pal and Mandal, 2012). However, kinases have been identified that assist in this activation that are members of the mammalian target of rapamycin complex 2 and DNA-dependent protein kinase family (Cantley, 2002).

Loss or mutation of the tumour suppressor phosphatase and tensin homologue (PTEN), mutation/overexpression of PI3K, activation or mutation of growth factor receptors and oncogenes, have been attributed to the alteration of the PI3K-Akt pathway in tumours of the colon, breast, brain, prostate, stomach and many other organs (Samuels and Waldman, 2010). Akt overexpression is associated with $57 \%$ sporadic colon tumours, which is higher than that in many other cancers. Moreover, activation of Akt was observed in colon cancer cells, but not in normal mucosa. Recently, amplification of Akt was found to be owing to an activating mutation in the PH domain of AKT1 (E17K) in melanoma, breast, colorectal and ovarian cancers (Miyaki et al, 2007; Nosho et al, 2008). Akt represents a potential target for cancer therapeutics owing to its association with resistance towards radiotherapy and chemotherapy (Bussink et al, 2008; Huang and Hung, 2009).

BI-69A11, an imidazole derivative, is a competitive Akt inhibitor. Previous studies suggest that BI-69A11 is more effective in inhibiting Akt and eliciting cell death in melanoma cells exhibiting elevated Akt activity (Gaitonde et al, 2009). BI-69A11 also causes dephosphorylation of Akt at Ser473, which disables Akt-HSP-90. This association prevents ubiquitin-mediated degradation of Akt. Recent studies also suggest that antitumour efficacy of BI-69A11 results from both the inhibition of the NF- $\kappa$ B pathway and the previously demonstrated inhibition of Akt (Feng et al, 2011; Barile et al, 2013).

Melanoma differentiation associated gene-7/interleukin-24 ( $m d a-7 /$ IL-24), an IL-10 family cytokine exhibits ubiquitous anticancer activity owing to its unique 'bystander' antitumour properties, which causes induction of apoptosis and growth inhibition in a wide array of human cancers (Dash et al, 2010). In contrast, $m d a-7 / \mathrm{IL}-24$ shows no apparent toxicity and marginal growth inhibitory effects in normal cells (Fisher, 2005; Lebedeva et al, 2005; Gupta et al, 2006a, b). Experiments confirm that interactions with the endoplasmic reticulum chaperone BiP/GRP78 are critical for $m d a-7 / \mathrm{IL}-24$ to induce apoptosis (Gupta et al, 2006a, b). Interestingly, expression of BiP/GRP78 is relatively higher in colon carcinoma than normal colonic tissue and colon adenoma (Langer et al, 2008; Xing et al, 2011). Additionally, mda7/IL-24 also abrogates cell cycle and induces apoptosis in colon cancer cell lines through an Akt-dependent pathway. Here we hypothesised that BI-69A11, a novel Akt inhibitor, would induce apoptosis of colon cancer cells by downregulating Akt that in turn would activate BAX and caspase- 3 to induce apoptosis. BiP/GRP78 is overexpressed in colon cancer (Chang et al, 2012) and earlier studies showed that regulation of expression occurs through an Akt-dependent pathway (Dai et al, 2010; Gray et al, 2013). In present study, we demonstrate that the combination of BI-69A11 and Ad.5/3-mda-7 (a tropism-modified replication incompetent adenovirus expressing MDA-7/IL-24) enhances apoptosis through an Akt-dependent pathway. This data suggests possible applications of the combination of mda-7/IL-24 and Akt inhibition as a potential therapeutic strategy for colon cancer.

\section{MATERIALS AND METHODS}

Cell lines. Human colon cancer cell lines, HT29 and HCT15 cells were obtained from the National Centre for Cell Science (Pune, India) and cultured as recommended by the supplier.
Two additional colorectal carcinoma (CRC) cells HCT116 and SW480 were a kind gift from Dr Sushanta Roy Chowdhury (IICB, Kolkata, India). Cells were incubated at $37^{\circ} \mathrm{C}$ in a $5 \% \mathrm{CO}_{2}$ atmosphere, 95\% humidity in RPMI1640 (Gibco-BRL, Rockville, MD, USA) and McCoy-5A (Gibco-BRL) media supplemented with $10 \%$ heat inactivated FBS (Gibco-BRL).

Reagents. Stock solutions of $10 \mathrm{~mm}$ BI-69A11 (Langer et al, 2008; Xing et al, 2011), were dissolved in DMSO, stored at $-20^{\circ} \mathrm{C}$, and diluted in fresh medium just before use. Tropism-modified adenovirus expressing $m d a-7$ or empty vectors were described previously (Langer et al, 2008; Xing et al, 2011). For Western blotting analysis, the following antibodies were used: rabbit monoclonal anti-PARP, anti-XIAP, anti-AIF and anti-Bax, antiCaspase-3 (Cell Signaling Technology, Beverly, MA, USA), mouse monoclonal anti-pro-caspase-3 (BD Pharmingen, NJ, USA), mouse monoclonal anti- $\beta$-actin (Sigma-Aldrich, St Louis, MO, USA), and horseradish peroxidase-conjugated goat anti-rabbit IgG, goat anti-mouse IgG (Santa Cruz Biotechnology, Santa Cruz, CA, USA). Chemiluminescent peroxidase substrate, Propidium iodide, RNaseA and MTT reagents were purchased from Sigma-Aldrich.

Cell viability assays. Cell proliferation was determined by MTT assay as described previously (Sarkar et al, 2011). Briefly, 5000 cells per well were seeded in 96-well plate and treated with different concentrations of BI-69A11 $(0.1-10 \mu \mathrm{M})$ and MTT assays were performed at various time points. For combination studies, cells were first infected with Ad.5/3-vec or Ad.5/3-mda-7 for $6 \mathrm{~h}$ followed by treatment with/without varying concentrations of BI-69A11 $(0-5 \mu \mathrm{M})$ for $48 \mathrm{~h}$.

Cell cycle analysis. The cells were grown and treated with BI-69A11 for varying time points. Cells were fixed with $70 \%$ ethanol, treated with RNaseA $\left(100 \mu \mathrm{g} \mathrm{ml}^{-1}\right)$ and propidium iodide at a final concentration of $40 \mu \mathrm{g} \mathrm{ml}^{-1}$, and incubated for $45 \mathrm{~min}$ at $37^{\circ} \mathrm{C}$. Finally, the cells were analysed with the FACS Vantage SE (BD Corporation, Franklin Lakes, NJ, USA). Cell cycle was also analysed by using Annexin-FITC apoptosis detection kit (SigmaAldrich) as per manufacturer's protocol. Cell Quest software version $2.0(\mathrm{BD})$ was used for data analysis.

Morphological studies. After $24 \mathrm{~h}$ seeding on a coverslip, cells were treated with BI-69A11 for 12 and $24 \mathrm{~h}$. Fixed $(3.7 \%$ paraformaldehyde) cells were stained with DAPI as per manufacturer's instructions. To see the changes associated with apoptosis, cells were stained with calcein AM and ethidium homodimer-1 using the LIVE/DEAD Viability/Cytotoxicity kit (Life Technologies, Carlsbad, CA, USA) as per the manufacturer's instructions. Cells were analysed by confocal laser scanning microscopy (Olympus FluoView FV1000, Version 1.7.1.0, Shinjuku, Tokyo, Japan) and images were captured, digitised using FLUOVIEW 1000 (Version 1.2.4.0) imaging software (Olympus, Tokyo, Japan).

TUNEL assay. Terminal deoxynucleotidyl transferase dUTP nick end labelling (TUNEL) assays were performed using the ApopTag Peroxidase in situ Apoptosis Detection Kit (Promega, Madison, WI, USA) according to the instructions of the manufacturer. Propidium iodide was used as a counterstain. Cells were analysed by confocal laser scanning microscopy at $20 \times$ magnification.

Akt kinase assay. To study the kinase activity of Akt, an Akt kinase Assay was carried out as per the manufacturer's protocol (Cell Signaling Technology) (Mandal et al, 2005). The incorporation of phosphate into glycogen synthase kinase 3 was assessed by Western blotting analysis with an anti-phospho-specific GSK- $3 \alpha / \beta$ (Ser21/9) antibody. To assess the level of expression of GSK, parallel total cell lysates were analysed by Western blotting.

Treatment with insulin growth factor (IGF) to study phosphorylation. Cells were seeded in cell culture plates and incubated in 
$10 \%$ FBS medium overnight. The next day, the cells were washed and incubated in serum-free medium for $24 \mathrm{~h}$. The experimental and the control plates were treated with $5 \mu \mathrm{M}$ of BI-69A11 and with $0.1 \%$ DMSO, respectively for $1 \mathrm{~h}$. Cells were then activated with recombinant human IGF (100 $\mathrm{ng} \mathrm{ml}^{-1}$ ) for $30 \mathrm{~min}$, washed with PBS, and scraped with lysis buffer, Western blot was carried out as described below.

Protein isolation and Western blotting. The HT29 and HCT116 cells were grown and treated with $\mathrm{IC}_{50}$ value of BI-69A11 for 12, 24 and $48 \mathrm{~h}$, respectively, or with control treatment (0.1\% DMSO) in cell culture dishes for $48 \mathrm{~h}$. The cells were then scraped and lysed in NP-40 lysis buffer (Sigma-Aldrich) and Western Blotting was done with appropriate primary and secondary antibodies as previously described (Rajput et al, 2013).

Wound-healing assay. HT29 and HCT116 cell monolayer's grown to confluence on six-well plates were wounded by scratching with a pipette tip and then cultured in the presence or absence of BI-69A11 $\left(<\mathrm{IC}_{50}\right)$ for different time points. The wounds were photographed at $4 \times$ and healing was quantified by measuring the distance between the edges using Adobe Photoshop (Adobe Systems Inc, San Jose, CA, USA).

Boyden chamber invasion assay. Cell invasion was performed in a modified Boyden chamber (BD Bioscience, San Diego, CA, USA) as described previously (Sarkar et al, 2008), according to the manufacturer's instructions. The results are expressed as the per cent of migrated cells as compared with the control (untreated cells).

Chick chorioallantoic membrane (CAM) assay. To determine in vivo anti-angiogenic activity, CAM assays were performed as described previously (Ribatti et al, 2006). Fertilised chicken eggs were allowed to grow for 9 days in an egg incubator. A $1-\mathrm{cm}^{2}$ window was created in the eggshell. The shell membrane was removed to expose the CAM. Conditioned media was implanted on the CAM. After incubation for $72 \mathrm{~h}$, the upper eggshell was removed and the neovascular zones were photographed (Sarkar et al, 2010) and quantified by Volocity software Version 5.4.2. (Perkin Elmer, Waltham, MA, USA).

HUVEC cell assay. HUVEC cells were seeded at a density of 15000 cells per well on the polymerised Matrigel with or without $35-\mathrm{ng} \mathrm{ml}^{-1} \mathrm{bFGF}$ in the presence of various conditioned medias. Plates were incubated at $37^{\circ} \mathrm{C}$ and tube formation was measured as described earlier (Chen et al, 2009).

Tumour xenograft. Female athymic nude mice (Nude-Foxn $1^{\text {nu }}$ ) were purchased from Harlan Sprague Dawley Inc. (Dublin, VA, USA) and were maintained in VCU institutional animal facility in accordance with the American Association for Laboratory Animal Science (AALAS) guidelines. The Institutional Animal Care and Use Committee (IACUC) of VCU approved the experiments described in this article. Mice were allowed free access to standard laboratory rodent food and water. The mice used for the experiment were between $8-12$ weeks of age and $\sim 20$ g bodyweight. Subcutaneous xenografts were established in the flanks of athymic nude mice using HT29 $\left(1 \times 10^{7}\right)$ cells. When tumours reached a volume of $100 \mathrm{~mm}^{3}$, mice were randomised and divided into four groups of five-mice per group. These four groups of animals were treated as follows: (i) Ad.5/3-vec $\left(1 \times 10^{8} \mathrm{pfu}\right)$; (ii) Ad.5/3-mda-7 $\left(1 \times 10^{8} \mathrm{pfu}\right)$; (iii) $\mathrm{BI}-69 \mathrm{~A} 11$ (15 mg per $\mathrm{kg}$ body-weight); (iv) Ad.5/3-mda-7 + BI-69A11. The adenoviruses (total nine injections in 3 weeks) and BI-69A11 (3 times per week) were administered as intratumoural and intraperitoneal injections, respectively. Tumour volume was measured twice weekly by calipers, using the equation: $(A)\left(B^{2}\right) \pi / 6$, where $A$ was the length of the longest aspect of the tumour, and $\mathrm{B}$ was the length of the tumour perpendicular to A (Dash et al, 2011).
Immunohistochemistry. For immunohistochemical analysis, tumour specimens were fixed in formalin and embedded in paraffin and sectioned. Immunostaining was performed as described previously with different antibodies including anti-pAkt (Ser473), anti-Akt, anti-Ki-67, and anti-CD31, anti-pribosomal-S6 protein and anti-ribosomal-S6. TUNEL Assay was carried out in the tissue as per manufacturer's protocol.

\section{RESULTS}

BI-69A11 inhibits in vitro cell proliferation in a dose- and timedependent manner in multiple colon cancer cell lines. The ability of BI-69A11 to inhibit cell proliferation of HT29, HCT15, HCT116 and SW480 CRC cells was determined by MTT assay (Figure 1A). The $\mathrm{IC}_{50}$ values for HT29, HCT15, HCT116 and SW480 are $8.083 \pm 0.332, \quad 2.074 \pm 0.102, \quad 5.360 \pm 0.144$ and $9.896 \pm 0.995$, respectively for $12 \mathrm{~h}$, and $5.172 \pm 0.063$, $1.838 \pm 0.118,3.393 \pm 0.069$ and $2.635 \pm 0.420$, respectively for $24 \mathrm{~h}$, and $2.540 \pm 0.154,1.485 \pm 0.125,1.973 \pm 0.111,2.255 \pm 0.353$, respectively for $48 \mathrm{~h}$. Live dead assays also reflected a decrease in the number of viable cells in a time-dependent manner in both HT29 and HCT116 cells following treatment with the $\mathrm{IC}_{50}$ of BI-69A11 (Figure 1B and Supplementary Figure S2).

To study the chronology of the cellular and molecular events occurring after BI-69A11 treatment, cell cycle analysis using flow cytometry was performed (Figure 1C; Supplementary Figure S1). This experiment indicated a substantial accumulation in sub G0/G1 of both cell lines during different time intervals. In the case of HCT116 cells, BI-69A11 treatment produced a substantial increase in sub G0/G1 cells (47.1\%) compared with the control (2.4\%). Similarly, for HT29 cells, BI-69A11 caused a $52.7 \%$ accumulation of cells in the sub G0/G1 phase $v s 1.03 \%$ in control (Figure 1C and Supplementary Figure S1). These data indicate that BI-69A11 induces apoptosis in CRC cells.

BI-69A11 induces apoptosis in CRC cells. The possibility that growth inhibition of BI-69A11 was owing to induction of apoptosis was further suggested by DAPI staining (Figure 2). Treatment with DMSO did not appreciably induce apoptosis, but typical morphological changes associated with apoptosis, including cell shrinkage, apoptosome formation and DNA fragmentations were observed in BI-69A11-treated HT29 and HCT116 cells (Figure 2A). TUNEL assays further documented these apoptotic events. The increase in TUNEL-positive cells (green cells) was observed in BI-69A11-treated HT29 and HCT116 cells (Figure 2B; Supplementary Figure S3).

Activation of pro-caspase- 3 is a critical mediator of apoptosis resulting in proteolytic cleavage of the nuclear enzyme PARP. A decrease in the level of pro-caspase- 3 along with an increase in cleaved PARP was observed in HT29 and HCT116 cells (Figure 2C). Induction of Bcl-2 promoter activity by IGF-1 occurs via a $\mathrm{PKB} / \mathrm{Akt}$ pathway involving the cyclic AMP-response element binding protein transcription factor. Therefore, we checked the expression of BAX, a pro-apoptotic protein that is regulated through a Bcl-2 mediated pathway. The level of BAX as well as AIF (another pro-apoptotic protein) was increased in a time-dependent manner (Figure 2C). Moreover, a decrease in the level of XIAP was observed that also occurred in an Akt-dependent manner as reported earlier (Dan et al, 2004). Flow cytometry assays with Annexin-V-FITC/PI provided further confirmation that the numbers of apoptotic cells, i.e., Annexin-V-FITC + apoptotic cells, were increased in a time-dependent manner in the treated groups (Figure 2D), which was consistent with the earlier described results obtained through MTT growth assays as well as live dead cell assays. 
A

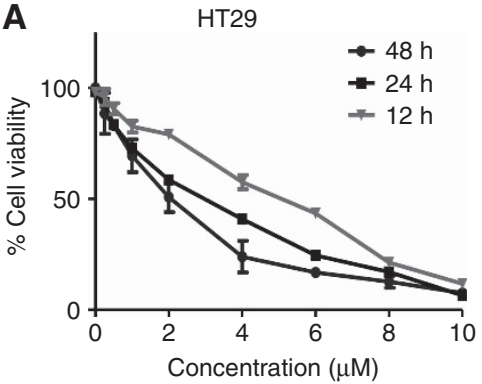

HCT15

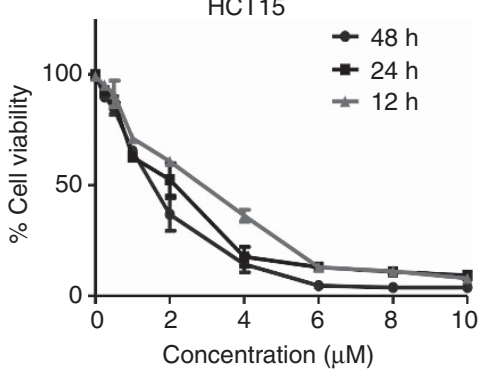

HCT116

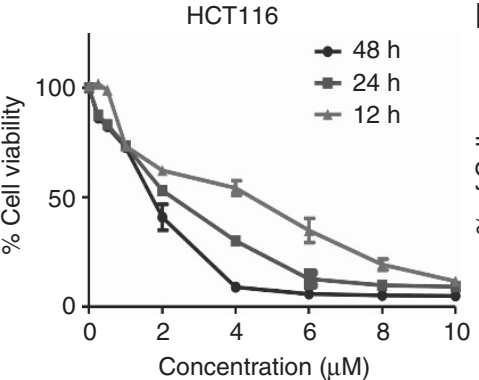

SW480

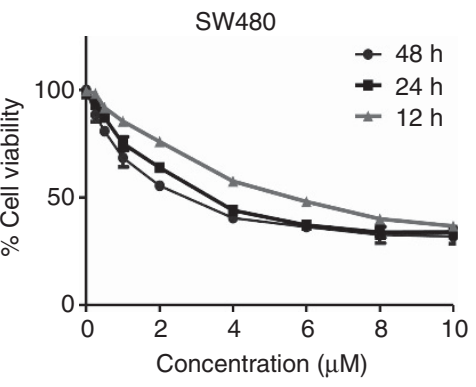

B
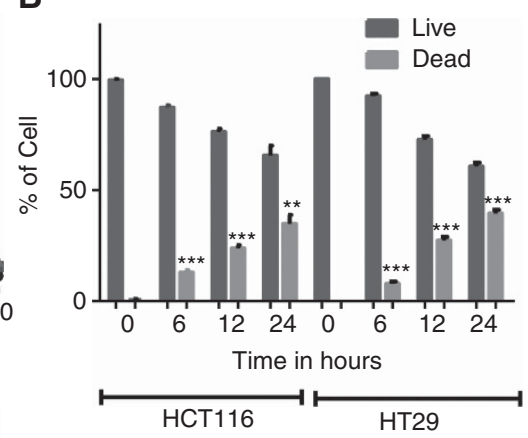

C

\begin{tabular}{|c|r|r|r|r|r|r|r|r|r|r|}
\hline \multirow{2}{*}{ Cell cycle } & \multicolumn{4}{|c|}{ HCT116 } & \multicolumn{5}{c|}{ HT29 } \\
\cline { 2 - 12 } & Control & \multicolumn{1}{|c|}{$3 \mathrm{~h}$} & $6 \mathrm{~h}$ & \multicolumn{1}{c|}{$12 \mathrm{~h}$} & $24 \mathrm{~h}$ & Control & $3 \mathrm{~h}$ & $6 \mathrm{~h}$ & $12 \mathrm{~h}$ & $24 \mathrm{~h}$ \\
\hline G0/G1 & 2.49 & 15.11 & 16.27 & 21.91 & 47.16 & 1.03 & 4.61 & 11.03 & 23.29 & 52.71 \\
\hline G1 & 40.30 & 30.88 & 35.40 & 35.65 & 29.26 & 59.6 & 44.7 & 31.79 & 29.69 & 23.53 \\
\hline $\mathrm{S}$ & 8.77 & 8.53 & 11.90 & 9.21 & 5.17 & 9.36 & 7.82 & 8.11 & 5.76 & 4.02 \\
\hline G2/M & 35.93 & 32.15 & 28.43 & 25.25 & 14.37 & 37.18 & 36.41 & 41.55 & 35.88 & 17.18 \\
\hline
\end{tabular}

Figure 1. Anti-proliferative effect of BI-69A11 on colon cancer cells. (A) Dose-dependent growth inhibitory effects of BI-69A11 on colorectal cancer cell lines. HCT116, HT29, HCT15 and SW480 cells were treated with various concentrations of BI-69A11 and incubated for 12, 24 and $48 \mathrm{~h}$, respectively, and MTT assays were performed. Points, average \pm s.d. of three different experiments each performed in triplicate, $P<0.05$. (B) The indicated cells were treated with an $\mathrm{IC}_{50}$ dose of BI-69A11 for indicated time (hrs). Cells were stained with calcein AM and ethidium bromide and images were captured. Graphical representations of live and dead cells in the experiment are shown as histograms; ${ }^{\star} P<0.05,{ }^{\star \star} P<0.01$, $\star \star \star P<0.001$ represents level of significance with respect to control. (C) Cell cycle analysis was performed by treating the indicated cells with an $\mathrm{IC}_{50}$ dose of $\mathrm{BI}-69 \mathrm{~A} 11$. Cells were exposed to the indicated concentrations of BI-69A11 for 3, 6, 12 and $24 \mathrm{~h}$ followed by propidium iodide staining. The data represent the percentage accumulation of cells in each phase and are representative of three independent experiments.

Effect of BI-69A11 on phosphorylation of Akt and its downstream targets in cancer cells. Akt is activated owing to phosphorylation at Ser473 and Thr308 sites in the regulatory and activation loop of Akt kinase. Experiments showed that BI69A11 downregulated IGF-mediated phosphorylation of Ser473Akt and Thr308-Akt without affecting the total amount of Akt (Figure $3 \mathrm{~A}$ ). In addition, a significant decrease in IGF-induced phosphorylation at both Ser473 and Thr308 residue in the case of HCT116 and HT29 cells was evident after BI-69A11 treatment (Figure 3B). However, the decrease in level of phosphorylation of Ser473 and Thr308 was almost similar in HCT116 cells, whereas the decrease in the level of phosphorylation of Thr308 was more pronounced than Ser473 in the case of HT29 cells. To determine the effect of BI-69A11 on Akt kinase activity, cells were treated with BI-69A11 and kinase activity was evaluated. The results obtained in this experiment were compared with another Akt inhibitor GSK690693, used as a positive control. Figure 3C confirms a decrease in Akt kinase activity in BI-69A11-treated HCT116 cells compared with the control. Histogram analysis (Figure 3D) showed that the inhibition by BI-69A11 was almost equal to that of the GSK690693-treated sample. However in the case of HT29, the inhibitory effect of BI-69A11 was significantly less compared with the inhibition in HCT116. As inhibition of Akt could further affect its substrate phosphorylation, the effect of BI-69A11 on the downstream targets of Akt including
IGF-mediated phosphorylation was analysed by Western blotting. Figure 3E demonstrated that BI-69A11 treatment induced down-regulation of IGF-mediated phosphorylation of GSK-3 $\beta$, ribosomal-S6 and 4E-BP1without affecting the total level of GSK-3 $\beta$, ribosomal-S6 and 4E-BP1.

BI-69A11 inhibits cell migration and invasion capabilities of CRC cells. To study the inhibitory effect of BI-69A11 on cell migration, wound-healing assays were performed. At $48 \mathrm{~h}$, the wound was decreased in control cells, but still remained relatively larger in treated samples in both HCT116 and HT29 cultures (Figure 4A). However, less closure of the wound was observed in HT29 cells in control samples (Figure 4A). Boyden chamber assays were used to determine the effect of BI-69A11 on the invasion potential of HT29 cells. Treatment with BI-69A11 induced a significant $48 \%$ reduction $(P=0.0008)$ in invasion of the treated cells compared with the control cells (Figure 4C).

BI-69A11 enhances Ad.5/3-mda-7-induced growth inhibition. We also evaluated the combinatorial effect of BI-69A11 and $m d a-7 /$ IL-24 on colorectal cancer cell growth. Previous studies suggest that a sub-lethal dose of Ad.5/3-vec or Ad.5/3-mda-7 of 25 pfu per cell for HCT116 and 100 pfu per cell for HT29 cells caused no substantial or a minimal decrease in cell viability in these colon cancer lines (Lebedeva et al, 2007). Earlier reports also suggested that Ad.5/3-mda-7 alone showed limited effect on growth inhibition of two colon cancer cell lines (Lebedeva et al, 2007). 


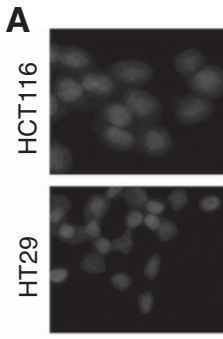

$\mathrm{Oh}$

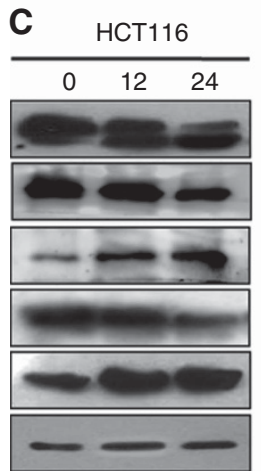

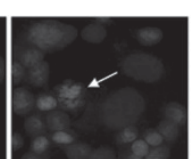
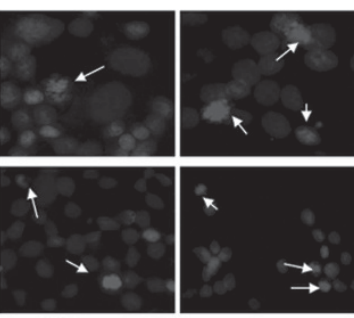

$12 \mathrm{~h}$

HT29

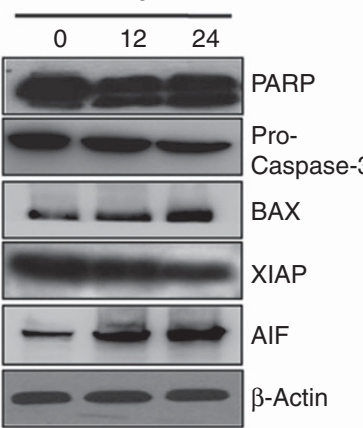

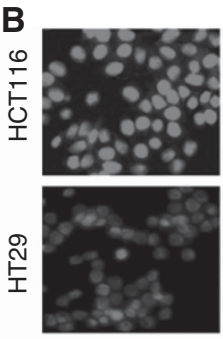

$\mathrm{Oh}$

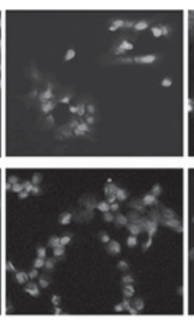

$12 \mathrm{~h}$
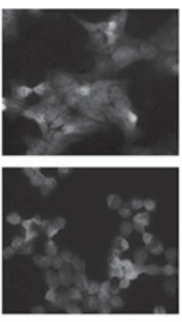

$24 \mathrm{~h}$

D

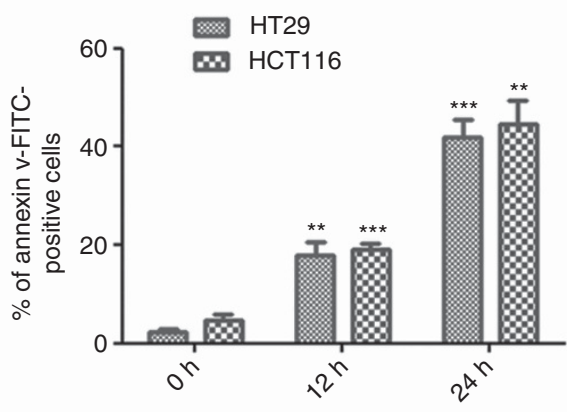

Figure 2. BI-69A11 induces apoptosis of colon cancer cells. (A) Characteristic apoptotic cells were detected in HCT116 and HT29 cell lines treated with BI-69A11 for 12 and $24 \mathrm{~h}$ by staining with DAPI. Photographs were taken under $20 \times$ magnifications using a confocal microscope. (B) TUNEL assays were performed as per the manufacturers' protocol on HCT116 and HT29 cells by treating cells for the indicated times with BI-69A11. The apoptotic cells with DNA fragmentation are stained positively as green nuclei and live cells with intact nuclei are stained as red nuclei. Both photographs were taken at $20 \times$ magnification and are representative of three separate experiments. (C) Western blotting of HCT116 and HT29 cells treated with BI-69A11 for the indicated times. Representative figures of three independent experiments. (D) Apoptosis was determined by flow-cytometric detection of Annexin V-FITC-positive cells treated for the indicated hours with BI-69A11. Representative histograms from three independent experiments are shown. The relative number of cells in each quadrant is given in per cent. ${ }^{\star \star} P<0.01,{ }^{* \star \star} P<0.001$ represents level of significance with respect to control.

We hypothesised that a combinatorial approach of Ad.5/3-mda-7 (Dash et al, 2010) and BI-69A11 might be useful in augmenting growth suppression and apoptosis. Following treatment with different doses of BI-69A11 $(0.1-5 \mu \mathrm{M})$ in combination with Ad.5/3-mda-7 (25 pfu per cell for both HCT116 and HT29), we observed a significant decrease $(P<0.01)$ of cell viability in both the cell lines (Figure 5A). We also observed that the combination of Ad.5/3-mda-7 resulted in a decrease of the $\mathrm{IC}_{50}$ value of BI-69A11 in both cell lines. The $\mathrm{IC}_{50}$ value of combinatorial treatment in HT29 and HCT116 was $0.644 \pm 0.065$ and $1.170 \pm 0.107$, respectively, as compared with $\mathrm{IC}_{50}$ value of BI-69 in HT29 and HCT116 of $2.540 \pm 0.154$ and $1.973 \pm 0.111$, respectively, after $48 \mathrm{~h}$ (Figure 5A).

BI-69A11 enhances Ad.5/3-mda-7-induced growth inhibition by blocking Akt. Further analysis suggested that the combination of BI-69A11 and Ad.5/3-mda-7 increased cleaved caspase-3 and cleaved PARP levels more than BI-69A11 or Ad.5/3-mda-7 alone (Figure 5B). Moreover, we observed an appreciable increase in the expression level of the apoptosis-inducing protein BAX and a concomitant decrease in the expression of the anti-apoptotic XIAP protein (Figure 5B) following combinatorial treatment with BI-69A11 and Ad.5/3-mda-7.

BI-69A11 inhibited Akt phosphorylation and Akt kinase activity in HCT116 and HT29 cells (Figure 3). We therefore investigated whether the combinatorial effect of BI-69A11 and Ad.5/3-mda-7 also promoted growth inhibition in an Akt-dependent manner. A significant reduction in p-Akt expression level and its downstream target p-S6 was observed following combinatorial treatment with BI-69A11 and Ad.5/3-mda-7 compared with cells treated with either agent alone (Figure 5B). However, no change in the total Akt level was observed.
The combination of Ad.5/3-mda-7 and BI-69A11 inhibits cell invasion and angiogenesis. To assess the in vivo anti-angiogenic effect of Ad.5/3-mda-7 and BI-69A11, alone and in combination, we used the CAM model. The angiogenic protein vascular endothelial growth factor (VEGF) promoted new blood vessel and capillary growth compared with Ad.5/3-vec-treated control (Figure 6). In contrast, inhibition of new blood vessel formation leading to a vascular zone was observed in Ad.5/3-mda-7, BI-69A11 and combination-treated samples (Figure 6A). As quantified in Figure $6 \mathrm{~B}$, it is evident that the extent of inhibition of angiogenesis is relatively higher in the combination-treated sample and the combination treatment also has the potential to vinhibit VEGF-induced angiogenesis as studied by CAM assay. Figure $6 \mathrm{~B}$ shows that the number of microvessels formed was significantly less in the combined-treated sample $(P=0.0016)$ compared with Ad.5/3-vec. A significant decrease in microvessels formation is also observed in individual drug-treated samples compared with Ad.5/3-vec $(P=0.0479)$. However, the decrease in Ad.5/3-mda-7 compared with Ad.5/3-vec is insignificant $(P=0.1582)$. Moreover, the decrease in microvessel formation is more significant in combined-treated samples as compared with individual drug-treated samples $(P=0.0034)$.

To investigate further the in vitro anti-angiogenic effect of the combination of Ad.5/3-mda-7 and BI-69A11, capillary formation assays were performed. In the presence of VEGF, formation of elongated and robust tube-like structures, much larger than the controls, were observed. However, treated samples showed a different trend corresponding to abrogation of the width and the length of endothelial tubes (Figure 6C). The decrease in the length and width of the capillaries was more pronounced in Ad.5/3mda-7 plus BI-69A11-treated cells as compared with the cells treated individually. Also the VEGF-induced Ad.5/3-mda-7 plus 
A

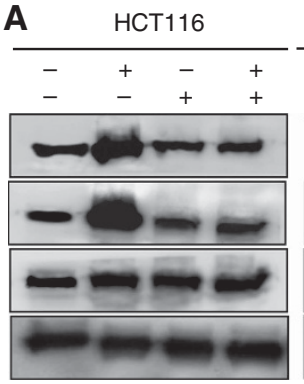

C HCT116

Control BI-69A11 GSK
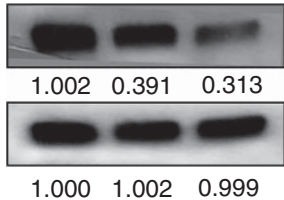

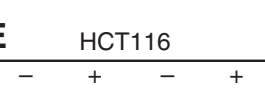

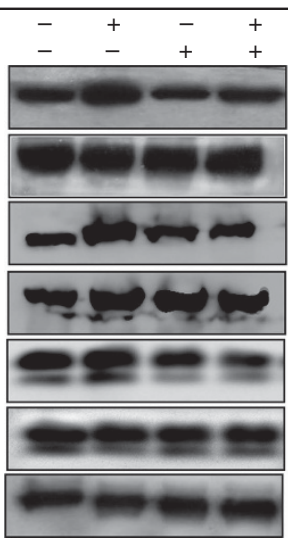

HT29
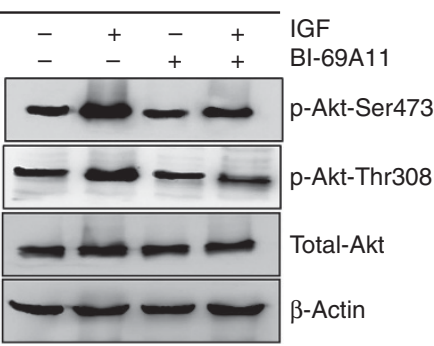

\begin{tabular}{ll} 
HT29 \\
\hline Control & BI-69A11 GSK
\end{tabular}
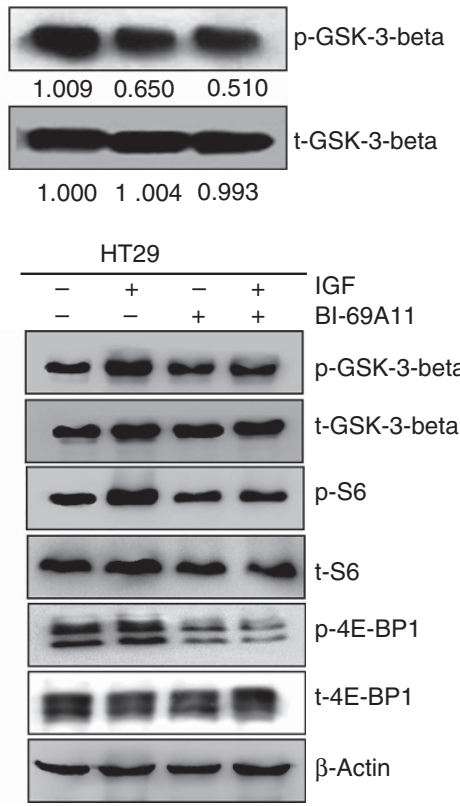

B
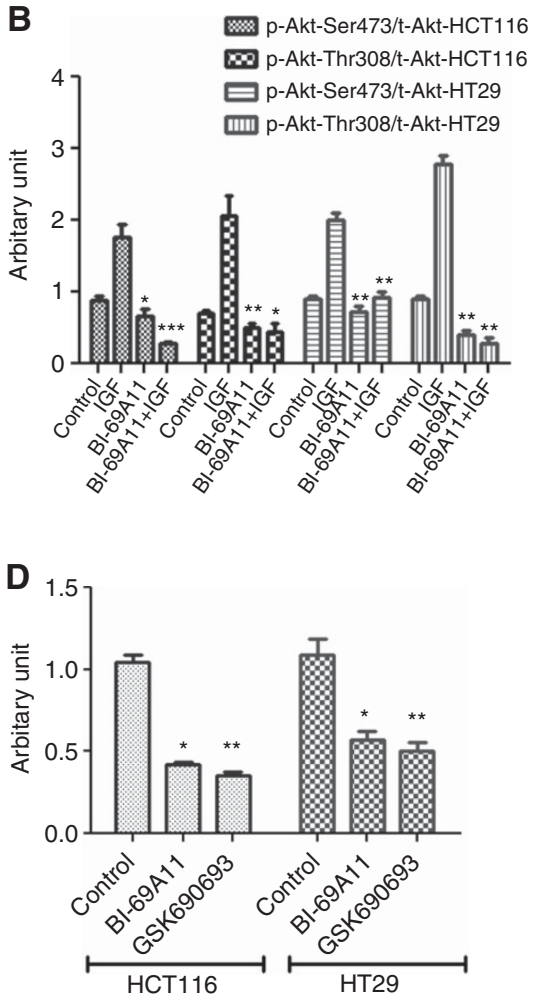

Figure 3. BI-69A11 inhibits Akt phosphorylation and phosphorylation of downstream targets of Akt in colon cancer cells. (A) and (E) HCT116 and HT29 colon cancer cells were untreated or treated with IGF (100 ng ml ${ }^{-1}$ ) and/or BI-69A11 (5 $\left.\mu \mathrm{M}\right)$ and equal amounts of protein cell lysates were analysed by Western blotting. (B) Representative densitometric analysis of Western blots as described in panel A and, the degree of inhibition by Bl-69A11 in both Ser473 and Thr308 residues, with respect to total Akt was determined. Data are means \pm s.e. of three random experiments; ${ }^{\star} P<0.05,{ }^{\star \star} P<0.01,{ }^{\star \star \star} P<0.001$ represent level of significance with respect to control. (C) HCT116 and HT29 cells were treated with or without $5 \mu \mathrm{m}$ of BI-69A11 or GSK690693 for $1 \mathrm{~h}$ and cell lysates were analysed for phospho-GSK-3 $\beta$ for Akt kinase activity and total GSK-3 $\beta$. (D) The expression of Akt kinase activity was determined by densitometry and is shown in the graph. Data are means \pm s.e. of three random experiments; ${ }^{\star} P<0.05,{ }^{\star \star} P<0.01,{ }^{\star \star \star} P<0.001$ represents level of significance with respect to control.

BI-69A11-treated samples displayed a similar response. These findings demonstrate a substantial impact of the combinatorial treatment with Ad.5/3-mda-7 and BI-69A11 on blocking angiogenesis. The extent of cumulative tube formation was significantly decreased in the combined-treated sample $(P=0.0012)$ as compared with the Ad.5/3-vec. A significant decrease was also observed in individual drug-treated samples $(P=0.0129)$ as compared with the Ad.5/3-vec (Figure 6D). However, the decrease in tube formation was more significant in combined-treated samples as compared with individual drugtreated samples $(P=0.0013)$.

Boyden chamber assays were performed to determine the effect of the combination on cell invasion. In the Ad.5/3-vec-treated group, a large number of HT29 cells migrated from the lower chamber to the upper chamber owing to its high-invasive nature (Figure 7A). The rate of invasion was decreased in the individualtreated cells and was reduced to the greatest extent in the combination-treated group. Figure $7 \mathrm{~B}$ provides the quantified data on the rate of invasion, which indicates the synergistic effect of the combination in comparison with the individual drug-treated or Ad.5/3-mda-7-infected samples.
The combination of Ad.5/3-mda-7 and BI-69A11 inhibits tumour growth in vivo. To evaluate the efficacy of the Ad.5/3mda-7 plus BI-69A11 treatment in vivo on human CRC cells, we employed a nude mouse HT29 xenograft model. In the Ad.5/3-vec group, the mean tumour volume was $1383.3 \pm 143.4$ after day 25 . On the other hand, in BI-69A11, Ad.5/3-mda-7 and the Ad.5/3mda-7 plus BI-69A11-treated groups; mean tumour volumes after 25 days were $187.3 \pm 156.9,364.5 \pm 174.6$ and $86.2 \pm 34.3$, respectively (Figure $8 \mathrm{~A}$ ). Thus, a significant decrease in the tumour volume was observed in the Ad.5/3-mda-7 plus BI-69A11-treated groups $(P=0.0054)$ compared with Ad.5/3-vec-treated group. A less significant trend is observed in the individual drug- or Ad.5/3mda-7-treated groups' compared with Ad.5/3-vec-treated group $(P=0.0249$ and 0.0876 , respectively). However, the decrease in tumour volume in combined-treated group is more significant compared with individual drug-treated groups $(P=0.010)$. A similar trend was observed in the case of tumour mass (Figure $8 \mathrm{~B}$ ). The mean tumour mass of the control group was $0.975 \pm 0.154$, whereas the mean tumour mass of the BI-69A11, Ad.5/3-mda-7 and Ad.5/3-mda-7 plus BI-69A11-treated groups after 25 days were $0.404 \pm 0.074,0.674 \pm 0.057$ and $0.174 \pm 0.066$, respectively. 
A
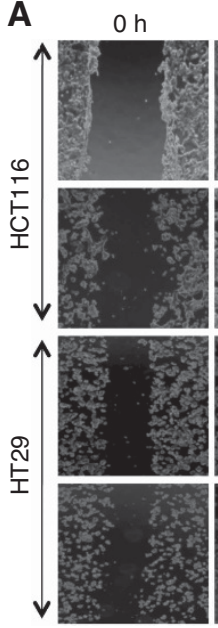

$12 \mathrm{~h}$

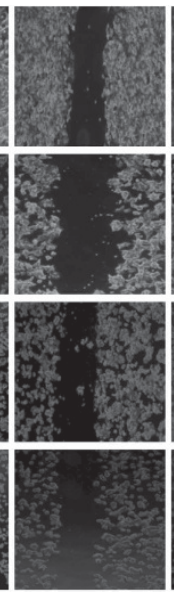

$24 \mathrm{~h}$

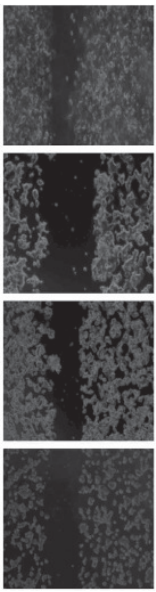

$48 \mathrm{~h}$

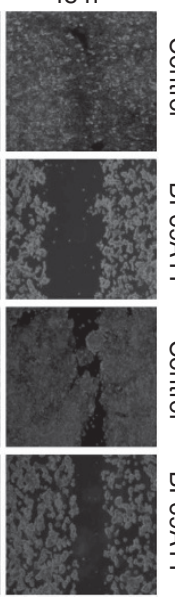

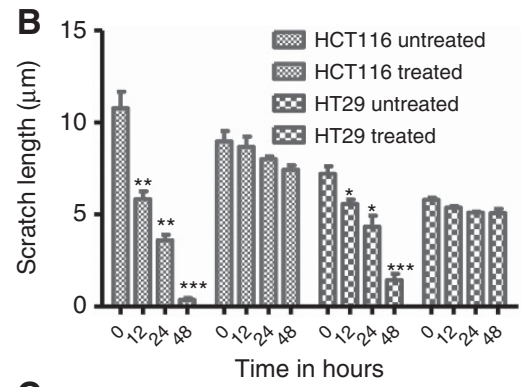

C

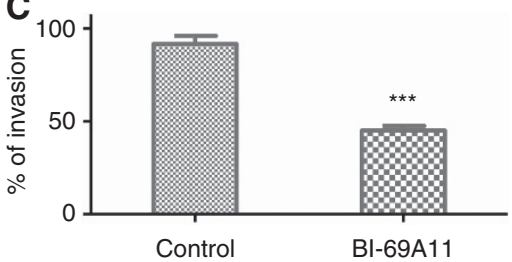

Figure 4. BI-69A11 suppresses the migration and invasion of colon cancer cells. (A) Microscopic observation of the growth of HCT116 and HT29 cells after sub-lethal dose of BI-69A11 exposure for the indicated times (h). A 'wound' was created with a pipette tip before treatment with $0.5 \mu \mathrm{M}$ $\mathrm{BI}-69 \mathrm{~A} 11$ containing culture medium. The data are representative of three independent experiments. Photographs were taken at $4 \times$

magnification. (B) Quantification of wound-healing results. Data are means \pm s.e. of three random widths along the wound with time. ${ }^{\star} P<0.05$, ${ }^{\star \star} P<0.01,{ }^{\star \star \star} P<0.001$ represent level of significance with respect to control. (C) Data represent the average percentage of cells ( \pm s.d.) invading the Boyden chamber inserts coated with Matrigel from three independent experiments, each performed in triplicate; ${ }^{* \star \star}$ represents $P<0.0001$. For this experiment HT29 cells were treated with $0.5 \mu \mathrm{M}$ of BI-69A11.

A

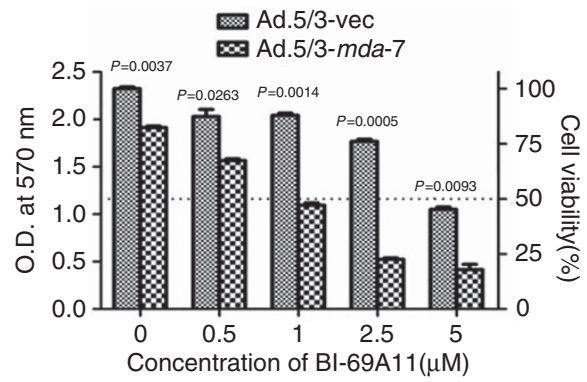

B

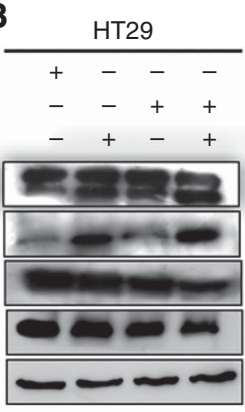

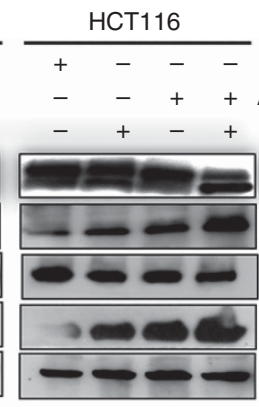

Ad.5/3-vec BI-69A11

PARP

BAX

XIAP

Caspase-3

$\beta$-Actin
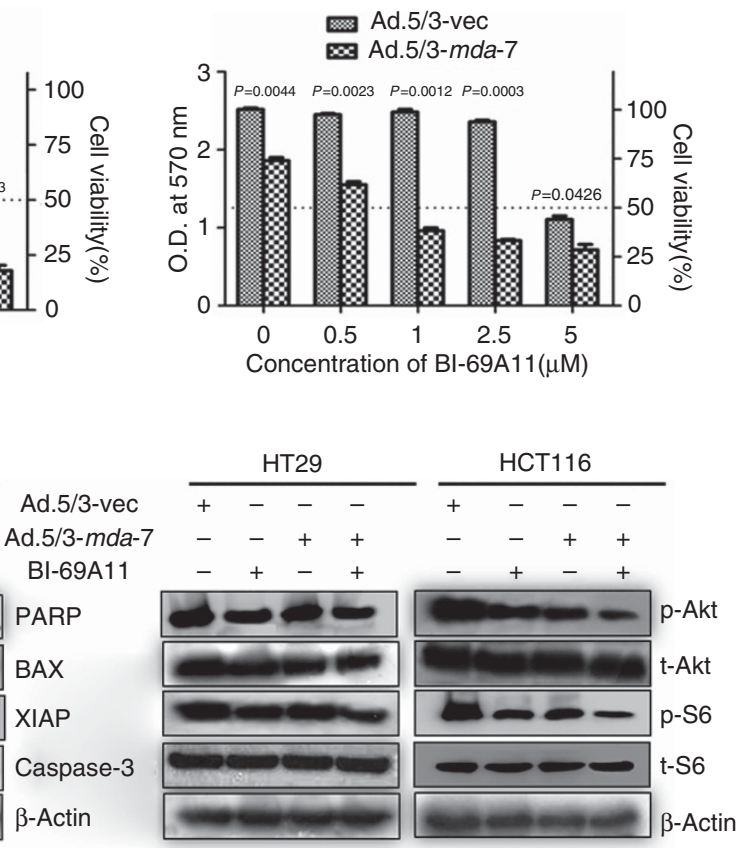

Figure 5. Combinatorial antitumour effects of Ad.5/3-mda-7 and BI-69A11 on colon cancer cells. (A) HT29 and HCT116 cells were infected with 25 pfu per cell of Ad.5/3-vec or Ad.5/3-mda-7 for $6 \mathrm{~h}$ and then treated with the indicated concentrations of BI-69A11 for $48 \mathrm{~h}$ and cell viability was monitored by MTT assay \pm s.d. ( $n=3$ ); $P<0.01$ for the BI-69A11- and Ad.5/3-mda-7-treated groups. (B) HT29 and HCT116 cells were infected with Ad.5/3-vec or Ad.5/3-mda-7 for $6 \mathrm{~h}$ and then exposed to the $\mathrm{IC}_{50}$ of BI-69A11 for $48 \mathrm{~h}$ and cells were lysed and Western blotting was performed with the indicated antibodies. Each experiment was performed in triplicate.

Here also a marked decrease in the tumour mass was observed in the case of the combined-treated than the individual drug- or Ad.5/ 3-mda-7-treated group. In addition to these observations, a marked decrease in Ki-67 and CD31 expression correlated well with the reduced rate of proliferation and angiogenesis observed in the groups receiving Ad.5/3-mda-7 plus BI-69A11 (Figure 8C). Supplementary Figure S4 also depicts the significant decrease in Ki-67 and CD31 expression levels observed in the combinationtreated samples $v s$ the individual-treated samples $(P<0.05)$.
To determine whether the combinatorial effect of Ad.5/3-mda-7 and BI-69A11 induced apoptosis in vivo, TUNEL assay was done. Mice receiving the Ad.5/3-mda-7 plus BI-69A11 treatment had an increased number of TUNEL-positive cells compared with the groups treated with a single agent (Figure 8C). Next, we determined the effect of combinatorial treatment on the Akt signalling pathway in the in vivo-derived tumour samples. Immunohistochemistry analysis demonstrated decreased levels of $\mathrm{p}$-Akt and $\mathrm{p}$-S6 expression in tumours treated with 
A

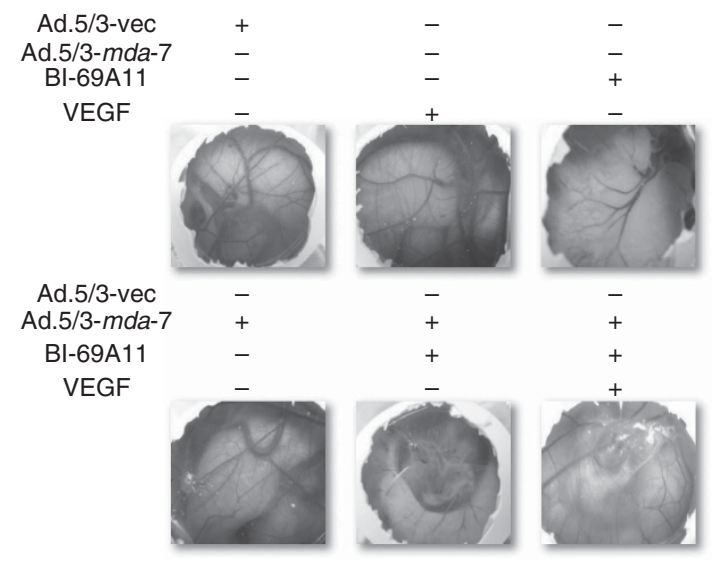

B

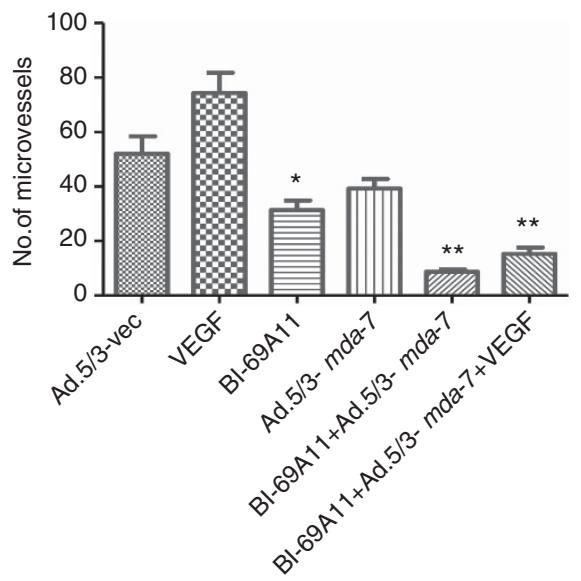

C
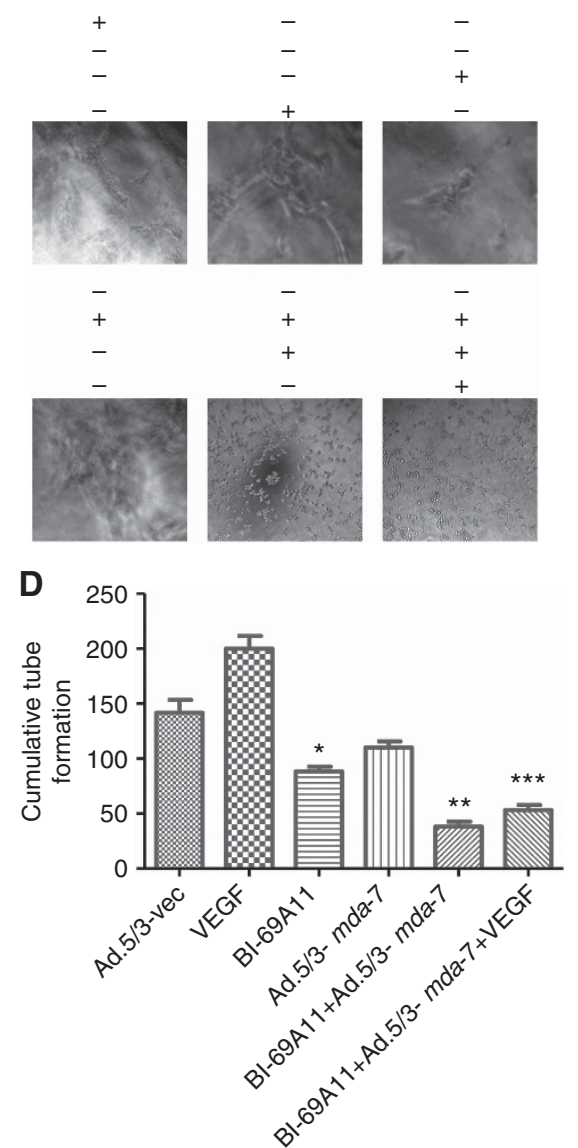

Figure 6. Combinatorial effect of Ad.5/3-mda-7 and BI-69A11 inhibits colon cancer cell migration, invasion and angiogenesis. (A) CAM assay was performed by treating fertilised (day 0) eggs with Ad.5/3-vec, VEGF, BI-69A11, Ad.5/3-mda-7, Ad-5/3-mda-7 and BI-69A11 or with Ad.5/3-mda-7, $\mathrm{BI}-69 \mathrm{~A} 11$ and VEGF. Photomicrographs were taken at $20 \times$ magnification. (B) Graphical representations of quantification of CAM assays as shown in panel A; (C) HUVEC cells were seeded in 96-well plates and treated with Ad.5/3-vec, VEGF as a positive control, BI-69A11, Ad.5/3-mda-7 and BI-69A11 or Ad.5/3-mda-7, VEGF, BI-69A11 and Ad.5/3-mda-7. Photomicrographs were taken at $40 \times$ magnification. (D) Graphical representations of quantification of HUVEC assays; ${ }^{\star} P<0.05,{ }^{\star \star} P<0.01,{ }^{\star \star \star} P<0.001$ represent level of significance with respect to Ad.5/3-vec in (B) and (D) by unpaired t-test.

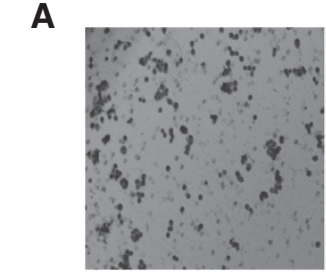

Ad.5/3-vec Ad.5/3-mda-7 BI-69A11
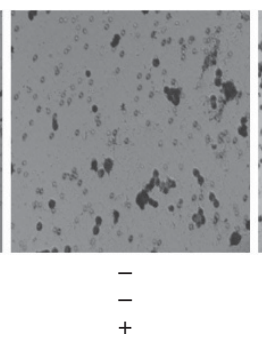

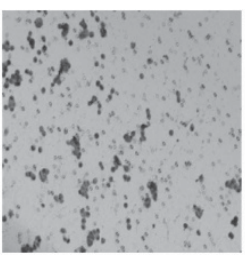

-
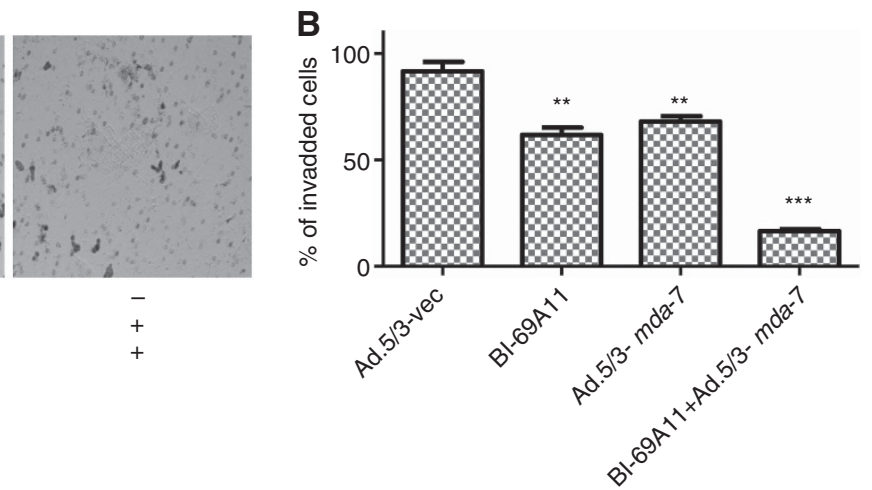

Figure 7. Effects of Ad.5/3-vec, Ad.5/3-mda-7 and BI-69A11 on invasion of HT29 colon carcinoma cells. (A) Photomicrographs of HT29 cell invasion assays following BI-69A11 and Ad.5/3-mda-7 infection alone and in combination. HT29 cells were treated with $0.5 \mu \mathrm{M} \mathrm{BI-96A11} \mathrm{and/or}$ Ad.5/3-mda-7 (25 pfu per cell) for $48 \mathrm{~h}$. Photographs were taken at $10 \times$ magnification. (B) Data represent the average percentage of cells ( \pm s.d.) invading the Boyden chamber inserts coated with Matrigel of three different experiments, each performed in triplicate; ${ }^{\star \star} P<0.01$ and ${ }^{\star \star \star} P<0.001$ represent level of significance with respect to Ad.5/3-vec.

Ad.5/3-mda-7 plus BI-69A11 (Figure 8C). No changes in total Akt and S6 levels were observed. Supplementary Figure S4 provides diagrammatic data indicating that $\mathrm{p}$-Akt and $\mathrm{p}$-S6 expression levels are significantly decreased in combination-treated samples $(P<0.05)$.

\section{DISCUSSION}

The present study evaluated the activities in human CRC cells of BI-69A11, a competitive and potent inhibitor of Akt that was 


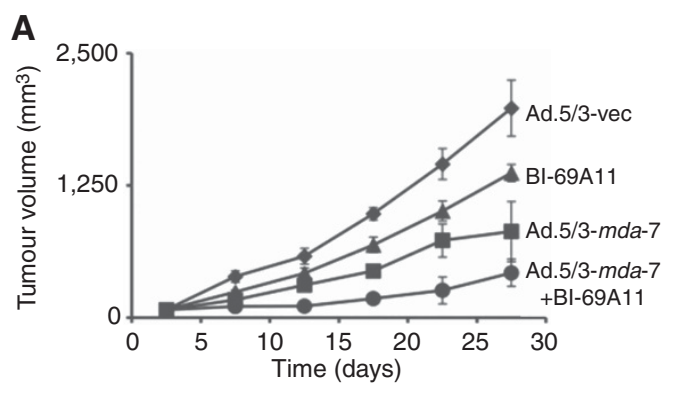

C
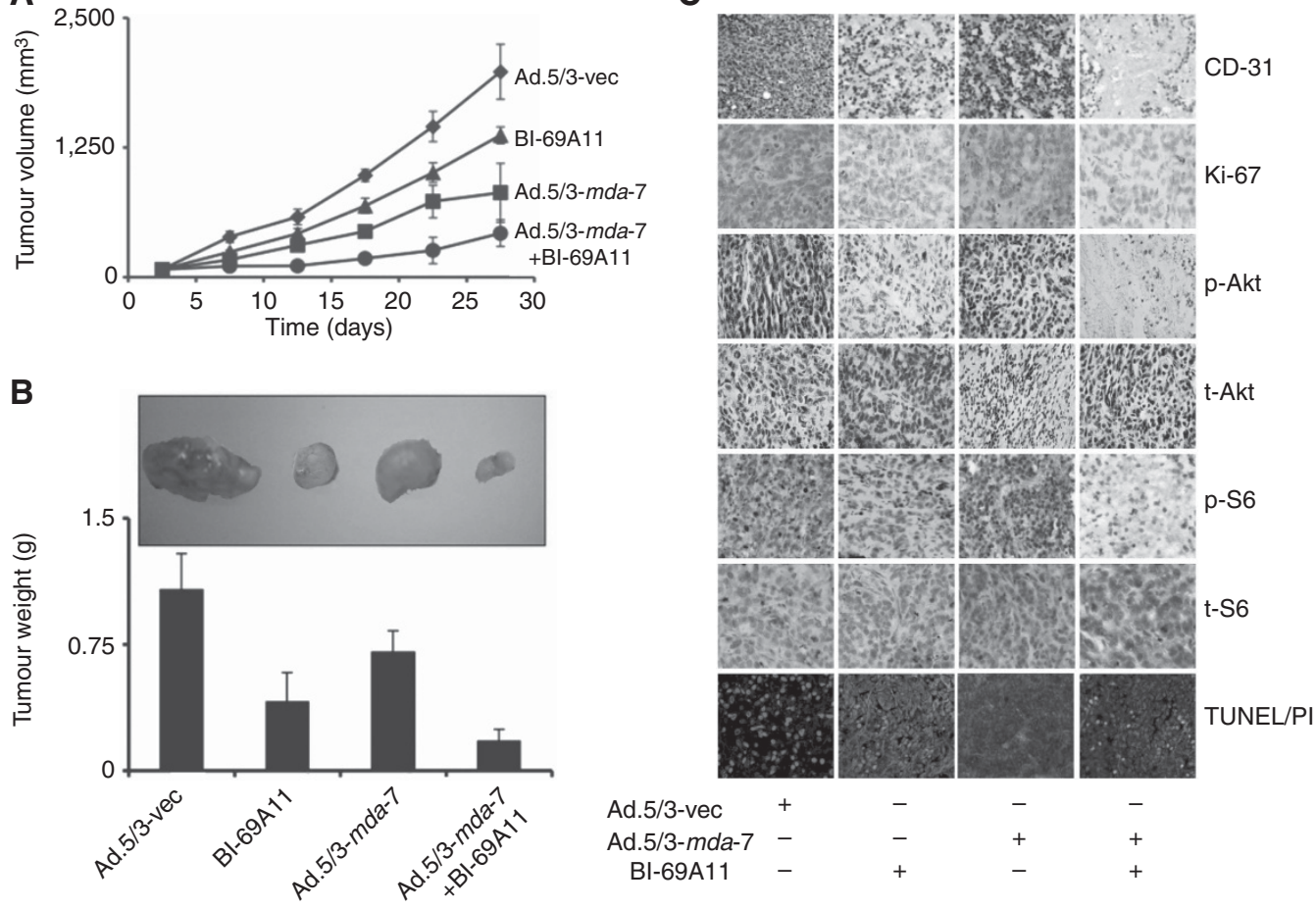

Figure 8. The combination of Ad.5/3-mda-7 and BI-69A11 inhibits the growth of human colon cancer xenografts in nude mice. (A) Measurement of HT29 xenograft tumour volumes at different time points. Data presented as mean \pm s.d. $(n=5), P<0.05$, when compared with the Ad.5/3-vectreated group. (B) Representative images and measurements of the tumour weights at the end of the study. Columns, mean \pm s.d. $(n=5)$. (C) Immunohistochemistry of BI-69A11- and Ad.5/3-mda-7-treated HT29 colon cancer xenografts. Paraffin-embedded sections of HT29 bearing tumours in nude mice were processed and IHC was done after staining with Akt, p-Akt, ribosomal-S6 protein and p-ribosomal-S6 protein to study the Akt pathway. Staining with Ki-67 and CD31 was used to monitor the anti-proliferative effect of single- and combination-treated tumours. TUNEL (Terminal deoxynucleotidyl transferase dUTP nick end labelling) assays were performed to study apoptosis. Pictures were taken at a magnification $20 \times$.

synthesised based on the reported crystal structure of AKT1 kinase and identified by using a virtual docking approach based on consensus scoring (Forino et al, 2005). Earlier reports suggested that competitive inhibition of Akt would result in the effective inhibition of growth of melanoma cells in vitro and in vivo in animal models (Gaitonde et al, 2009). PIK3CA mutation has been found in $32 \%$ of colon cancers and leads to the hyperactivation of the Akt pathway. Moreover, constitutively active AKT1 has a key role in the biology of CRC, with multiple factors associated with Akt activation. In this study, we report that BI-69A11 exerts anti-proliferative effect by inhibiting Akt phosphorylation and kinase activity. Additional studies indicate that BI-69A11 decreases cell viability mainly by triggering apoptosis, as evident by an increase in sub G0/G1 population of cells, characteristic morphological changes of apoptosis in the nucleus, cleavage of PARP and increase in BAX as well as an increase in TUNEL-positive cells in HCT116 and HT29 cells. HCT116 contains a PIK3CA mutation and a mutant K-ras gene and HT29 cells contain PIK3CA mutation, a B-Raf mutation and a wild type $\mathrm{K}$-ras gene. However the $\mathrm{IC}_{50}$ value is higher in HT29 cells, which might raise concern. Further results confirm that BI-69A11 inhibits Akt phosphorylation and Akt kinase activity. The decrease in kinase activity is relatively low in HT29 cells compared with HCT116 cells. The ability of Akt to phosphorylate its downstream targets including GSK-3 $\beta$, ribosomal-S6 protein and 4E-BP1 was markedly decreased in the presence of BI-69A11. BI-69A11 can suppress wound healing, angiogenesis (CAM assay), tumour cell invasion (Boyden chamber assay) and tumourigenesis in vivo in an animal model indicating multiple targets for inhibiting cancer phenotypes that are regulated by Akt pathway activation. In conclusion, BI-69A11 inhibits the downstream targets of Akt irrespective of substrate specificity.

Owing to the multiple signalling pathway alterations in human cancers that lead to chemotherapeutic resistance, inhibition of one target molecule/pathway may be insufficient because other components can compensate for the inhibited targeted molecule. It is accepted that combining Akt inhibitors with other cancer therapeutics is a promising way to improve cancer therapy. MK2206 in combination with other chemotherapeutic drugs including carboplatin, gemcitabine, 5FU and doxorubicin produce better antitumour effects than a monotherapy (Hirai et al, 2010). These combinations also have more profound effects on cancer cell lines expressing wild type K-ras than those expressing mutant K-ras (Gulhati et al, 2012). The second best-characterised RAS effector family molecules are PI3Ks, which play important roles, as mediators of RAS-driven cell survival and proliferation (Castellano and Downward, 2010). Melanoma differentiation associated gene-7/interleukin-24 functions as an efficient antitumour and apoptosis-inducing gene in diverse cancer cells in vitro and in vivo but its efficacy is attenuated to some degree in specific colorectal cancer cells. This could be owing to frequent K-ras mutations in CRCs that might impact on the ability of mda-7/IL24 to induce apoptosis (Bos et al, 1987). Previous reports suggest that a sub-lethal dose of Ad.5/3-mda-7 results in a minimal decrease in cell viability of HT29 (wild type K-ras) and HCT116 cells (mutant K-ras) (Lebedeva et al, 2007). As K-RAS acts through the PI3K-Akt-mediated pathway, we hypothesised that combining an Akt inhibitor with $m d a-7 /$ IL-24 could enhance the antitumour effect of Ad.5/3-mda-7. Currently, we show that combined treatment with sub-lethal doses of both Ad.5/3-mda-7 and 
BI-69A11 increase growth inhibition in both cell lines which was more pronounced in HT29 as compared with HCT116 cells.

The strategy that we employed involving a combination of Ad.5/3-mda-7 gene therapy with BI-69A11 efficiently enhanced antitumour effects against colon cancer cells. The growth inhibitory effects of this combination involved inhibition of the Akt pathway and were affected by K-ras mutation. This was further confirmed with increased cleavage of PARP, cleavage of caspase- 3 and upregulation of BAX expression with a concomitant decrease in XIAP expression. These data support the conclusion that this combination effectively induces apoptosis. Dual targeting of phosphorylation of Akt of colon cancer induces growth inhibition to a greater extent but with a relatively low sub-lethal dose of both BI-69A11 and Ad.5/3$m d a-7$. In the case of HT29, the decrease in the $\mathrm{IC}_{50}$ dose of BI$69 \mathrm{~A} 11$ is more profound in the presence of Ad.5/3-mda-7 than in HCT116.

Akt has an important role in regulating normal vascularisation and pathological angiogenesis (Jiang and Liu, 2008; Okumura et al, 2012). This is due to the activation of Akt, which induces VEGF and HIF-1 expression through its two downstream molecules HDM2 and p70S6K1 (Jiang and Liu, 2008). To evaluate the effect of this combination on angiogenesis, CAM and HUVEC assays were performed. In vitro and in vivo angiogenesis assays also confirmed the fact that the combination of BI-69A11 and Ad.5/3$m d a-7$ inhibits angiogenesis that might be mediated through inhibition of p70S6K1 kinase. Boyden chamber assays also supported the fact that the combination treatment inhibited cell invasion. Moreover, the combinatorial treatment markedly reduced in vivo tumour growth that was accompanied with decreased proliferation and angiogenesis, which was owing to decreased Akt phosphorylation. Thus, the combination treatment could be an effective therapeutic to prevent colorectal tumour growth and metastasis.

In summary, we presently demonstrate that targeting Akt and its downstream signalling pathways with BI-69A11 in combination with expression of the cancer-specific apoptosis-inducing cytokine gene $m d a-7 /$ IL-24 effectively diminishes the growth of human colorectal cancer cells in vitro and in vivo in nude mice, with respect to their K-ras status. BI-69A11 generally exerted minimal cytotoxic effects on normal cell lines even at a concentration of $10 \mu \mathrm{M}$ which is upper limit of the experimental concentration range $(0-10 \mu \mathrm{M})$. Combining BI-69A11 with Ad.5/3-mda-7 reduced cytotoxicity dramatically because lower doses were required when combining the Akt inhibitor with the therapeutic cytokineproducing virus. Moreover, combining Ad.5/3-mda-7 with BI-69A11 increased the therapeutic efficacy of Ad.5/3-mda-7 in colon cancer cells displaying either a wild type or mutant K-ras. These results suggest potential applications of this combinatorial approach for the therapy of colorectal cancer.

\section{ACKNOWLEDGEMENTS}

The present study was supported in part by National Institutes Health, National Cancer Institute Grant 1R01 CA097318 (PBF) and 1R01 CA168517 (MP and PBF). DS is a Harrison Scholar at the VCU Massey Cancer Centre. PBF holds the Thelma Newmeyer Corman Chair in Cancer Research in the VCU Massey Cancer Centre. We thank Dr Santanu Dasgupta for helpful discussions and proofing of this manuscript.

\section{CONFLICT OF INTEREST}

The authors declare no conflict of interest.

\section{REFERENCES}

Barile E, De SK, Feng Y, Chen V, Yang L, Ronai Z, Pellecchia M (2013) Synthesis and SAR Studies of Dual AKT/NF-kappaB Inhibitors Against Melanoma. Chem Biol Drug Des 82(5): 520-533.

Bellacosa A, Kumar CC, Di Cristofano A, Testa JR (2005) Activation of AKT kinases in cancer: implications for therapeutic targeting. Adv Cancer Res 94: $29-86$.

Bos JL, Fearon ER, Hamilton SR, Verlaan-de Vries M, van Boom JH, van der Eb AJ, Vogelstein B (1987) Prevalence of ras gene mutations in human colorectal cancers. Nature 327(6120): 293-297.

Bussink J, van der Kogel AJ, Kaanders JH (2008) Activation of the PI3-K/AKT pathway and implications for radioresistance mechanisms in head and neck cancer. Lancet Oncol 9(3): 288-296.

Cantley LC (2002) The phosphoinositide 3-kinase pathway. Science 296(5573): 1655-1657.

Castellano E, Downward J (2010) Role of RAS in the regulation of PI 3-kinase. Curr Top Microbiol Immunol 346: 143-169.

Chang YJ, Huang YP, Li ZL, Chen CH (2012) GRP78 knockdown enhances apoptosis via the down-regulation of oxidative stress and Akt pathway after epirubicin treatment in colon cancer DLD-1 cells. PLoS One 7(4): e35123.

Chen Z, Htay A, Dos Santos W, Gillies GT, Fillmore HL, Sholley MM, Broaddus WC (2009) In vitro angiogenesis by human umbilical vein endothelial cells (HUVEC) induced by three-dimensional co-culture with glioblastoma cells. J Neurooncol 92(2): 121-128.

Dai RY, Chen SK, Yan DM, Chen R, Lui YP, Duan CY, Li J, He T, Li H (2010) PI3K/Akt promotes GRP78 accumulation and inhibits endoplasmic reticulum stress-induced apoptosis in HEK293 cells. Folia Biol (Praha) 56(2): 37-46.

Dan HC, Sun M, Kaneko S, Feldman RI, Nicosia SV, Wang HG, Tsang BK, Cheng JQ (2004) Akt phosphorylation and stabilization of X-linked inhibitor of apoptosis protein (XIAP). J Biol Chem 279(7): 5405-5412.

Dash R, Azab B, Quinn BA, Shen X, Wang XY, Das SK, Rahmani M, Wei J, Hedvat M, Dent P, Dmitriev IP, Curiel DT, Grant S, Wu B, Stebbins JL, Pellecchia M, Reed JC, Sarkar D, Fisher PB (2011) Apogossypol derivative BI-97C1 (Sabutoclax) targeting Mcl-1 sensitizes prostate cancer cells to mda-7/IL-24-mediated toxicity. Proc Natl Acad Sci USA 108(21): 8785-8790.

Dash R, Bhutia SK, Azab B, Su ZZ, Quinn BA, Kegelmen TP, Das SK, Kim K, Lee SG, Park MA, Yacoub A, Rahmani M, Emdad L, Dmitriev IP, Wang XY, Sarkar D, Grant S, Dent P, Curiel DT, Fisher PB (2010) mda-7/ IL-24: a unique member of the IL-10 gene family promoting cancertargeted toxicity. Cytokine Growth Factor Rev 21(5): 381-391.

Dash R, Dmitriev I, Su ZZ, Bhutia SK, Azab B, Vozhilla N, Yacoub A, Dent P, Curiel DT, Sarkar D, Fisher PB (2010) Enhanced delivery of mda-7/IL-24 using a serotype chimeric adenovirus (Ad.5/3) improves therapeutic efficacy in low CAR prostate cancer cells. Cancer Gene Ther 17(7): 447-456.

Feng Y, Barile E, De SK, Stebbins JL, Cortez A, Aza-Blanc P, Villanueva J, Heryln M, Krajewski S, Pellecchia M, Ronai ZA, Chiang GG (2011) Effective inhibition of melanoma by BI-69A11 is mediated by dual targeting of the AKT and NF-kappaB pathways. Pigment Cell Melanoma Res 24(4): 703-713.

Fisher PB (2005) Is mda-7/IL-24 a 'magic bullet' for cancer? Cancer Res 65(22): 10128-10138.

Forino M, Jung D, Easton JB, Houghton PJ, Pellecchia M (2005) Virtual docking approaches to protein kinase B inhibition. J Med Chem 48(7): 2278-2281.

Gaitonde S, De SK, Tcherpakov M, Dewing A, Yuan H, Riel-Mehan M, Krajewski S, Robertson G, Pellecchia M, Ronai Z (2009) BI-69A11mediated inhibition of AKT leads to effective regression of xenograft melanoma. Pigment Cell Melanoma Res 22(2): 187-195.

Gray MJ, Mhawech-Fauceglia P, Yoo E, Yang W, Wu E, Lee AS, Lin YG (2013) AKT inhibition mitigates GRP78 (glucose-regulated protein) expression and contribution to chemoresistance in endometrial cancers. Int J Cancer 133(1): 21-30.

Gulhati P, Zaytseva YY, Valentino JD, Stevens PD, Kim JT, Sasazuki T, Shirasawa S, Lee EY, Weiss HL, Dong J, Gao T, Evers BM (2012) Sorafenib enhances the therapeutic efficacy of rapamycin in colorectal cancers harboring oncogenic KRAS and PIK3CA. Carcinogenesis 33(9): 1782-1790.

Gupta P, Su ZZ, Lebedeva IV, Sarkar D, Sauane M, Emdad L, Bachelor MA, Grant S, Curiel DT, Dent P, Fisher PB (2006a) mda-7/IL-24: multifunctional cancer-specific apoptosis-inducing cytokine. Pharmacol Ther 111(3): 596-628. 
Gupta P, Walter MR, Su ZZ, Lebedeva IV, Emdad L, Randolph A, Valerie K, Sarkar D, Fisher PB (2006b) BiP/GRP78 is an intracellular target for MDA-7/IL-24 induction of cancer-specific apoptosis. Cancer Res 66(16): 8182-8191.

Hanada M, Feng J, Hemmings BA (2004) Structure, regulation and function of PKB/AKT-a major therapeutic target. Biochim Biophys Acta 1697(1-2): 3-16.

Hirai H, Sootome H, Nakatsuru Y, Miyama K, Taguchi S, Tsujioka K, Ueno Y, Hatch H, Majumder PK, Pan BS, Kotani H (2010) MK-2206, an allosteric Akt inhibitor, enhances antitumor efficacy by standard chemotherapeutic agents or molecular targeted drugs in vitro and in vivo. Mol Cancer Ther 9(7): 1956-1967.

Huang WC, Hung MC (2009) Induction of Akt activity by chemotherapy confers acquired resistance. J Formos Med Assoc 108(3): 180-194.

Jiang BH, Liu LZ (2008) AKT signaling in regulating angiogenesis. Curr Cancer Drug Targets 8(1): 19-26.

Langer R, Feith M, Siewert JR, Wester HJ, Hoefler H (2008) Expression and clinical significance of glucose regulated proteins GRP78 (BiP) and GRP94 (GP96) in human adenocarcinomas of the esophagus. BMC Cancer 8: 70.

Lebedeva IV, Sauane M, Gopalkrishnan RV, Sarkar D, Su ZZ, Gupta P, Nemunaitis J, Cunningham C, Yacoub A, Dent P, Fisher PB (2005) mda-7/IL-24: exploiting cancer's Achilles' heel. Mol Ther 11(1): 4-18.

Lebedeva IV, Su ZZ, Emdad L, Kolomeyer A, Sarkar D, Kitada S, Waxman S, Reed JC, Fisher PB (2007) Targeting inhibition of K-ras enhances Ad.mda-7-induced growth suppression and apoptosis in mutant K-ras colorectal cancer cells. Oncogene 26(5): 733-744.

Mandal M, Kim S, Younes MN, Jasser SA, El-Naggar AK, Mills GB, Myers JN (2005) The Akt inhibitor KP372-1 suppresses Akt activity and cell proliferation and induces apoptosis in thyroid cancer cells. Br J Cancer 92(10): 1899-1905.

Miyaki M, Iijima T, Yamaguchi T, Takahashi K, Matsumoto H, Yasutome M, Funata N, Mori T (2007) Mutations of the PIK3CA gene in hereditary colorectal cancers. Int J Cancer 121(7): 1627-1630.

Nosho K, Kawasaki T, Ohnishi M, Suemoto Y, Kirkner GJ, Zepf D, Yan L, Longtine JA, Fuchs CS, Ogino S (2008) PIK3CA mutation in colorectal cancer: relationship with genetic and epigenetic alterations. Neoplasia 10(6): 534-541.
Okumura N, Yoshida H, Kitagishi Y, Murakami M, Nishimura Y, Matsuda S (2012) PI3K/AKT/PTEN signaling as a molecular target in leukemia angiogenesis. Adv Hematol 2012: 843085.

Pal I, Mandal M (2012) PI3K and Akt as molecular targets for cancer therapy: current clinical outcomes. Acta Pharmacol Sin 33(12): 1441-1458.

Rajput S, Kumar BN, Sarkar S, Das S, Azab B, Santhekadur PK, Das SK, Emdad L, Sarkar D, Fisher PB, Mandal M (2013) Targeted apoptotic effects of thymoquinone and tamoxifen on XIAP mediated Akt regulation in breast cancer. PLoS One 8(4): e61342.

Ribatti D, Nico B, Vacca A, Presta M (2006) The gelatin spongechorioallantoic membrane assay. Nat Protoc 1(1): 85-91.

Samuels Y, Waldman T (2010) Oncogenic mutations of PIK3CA in human cancers. Curr Top Microbiol Immunol 347: 21-41.

Sarkar D, Park ES, Emdad L, Lee SG, Su ZZ, Fisher PB (2008) Molecular basis of nuclear factor-kappaB activation by astrocyte elevated gene-1. Cancer Res 68(5): 1478-1484.

Sarkar S, Mazumdar A, Dash R, Sarkar D, Fisher PB, Mandal M (2010) ZD6474, a dual tyrosine kinase inhibitor of EGFR and VEGFR-2, inhibits MAPK/ERK and AKT/PI3-K and induces apoptosis in breast cancer cells. Cancer Biol Ther 9(8): 592-603.

Sarkar S, Mazumdar A, Dash R, Sarkar D, Fisher PB, Mandal M (2011) ZD6474 enhances paclitaxel antiproliferative and apoptotic effects in breast carcinoma cells. J Cell Physiol 226(2): 375-384.

Vivanco I, Sawyers CL (2002) The phosphatidylinositol 3-Kinase AKT pathway in human cancer. Nat Rev Cancer 2(7): 489-501.

Xing X, Li Y, Liu H, Wang L, Sun L (2011) Glucose regulated protein 78 (GRP78) is overexpressed in colorectal carcinoma and regulates colorectal carcinoma cell growth and apoptosis. Acta Histochem 113(8): 777-782.

This work is published under the standard license to publish agreement. After 12 months the work will become freely available and the license terms will switch to a Creative Commons AttributionNonCommercial-Share Alike 3.0 Unported License.

Supplementary Information accompanies this paper on British Journal of Cancer website (http://www.nature.com/bjc) 